\title{
As rádios locais em Portugal - da génese do movimento à legalização
}

LUÍS BONIXE

ESE de Portalegre - Portugal - luis.bonixe@gmail.com Doutor em Ciências da Comunicação, especialização em Jornalismo, com uma tese defendida na Universidade Nova de Lisboa sobre jornalismo radiofónico.

\begin{abstract}
Resumo
O objetivo deste artigo é analisar a génese das rádios locais portuguesas. Olhamos em particular para o período compreendido entre 1977 e 1988, durante o qual emitiram sem licença e por isso foram apelidadas de rádios piratas. Analisamos, seguindo uma perspectiva histórica, as diversas dimensões das rádios locais em Portugal, tais como as iniciativas legislativas para a sua legalização, a propriedade, os conteúdos da programação e a informação. A análise efetuada permite-nos concluir que as rádios piratas portuguesas representaram um importante marco na história dos meios de comunicação social em Portugal no que diz respeito à diversidade e pluralismo do discurso público.
\end{abstract}

\section{Palavras-chave}

Rádios locais; rádios piratas, liberalização.

\begin{abstract}
This article proposes to analyse the genesis of the Portuguese local radio between 1977 and 1988 , period in witch they broadcast without permission. We analyse, according to a historical perspective, the different dimensions of the Portuguese local radio such as the legal efforts toward the legalization, their property, the programming and news. The article concludes that Portuguese local radio represents an important moment in the Portuguese media history by providing pluralism and diversity of public discourse.
\end{abstract}

\section{Keywords}

Local radio, pirate radio, liberalization.

Artigo recebido em 07/09/2012

Aprovado em 02/10/2012 


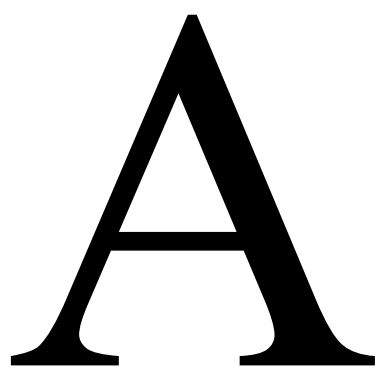

partir do final da década de 70 do século XX o setor da rádio em Portugal conhece uma agitação nunca antes vista com a proliferação por todo o país de centenas de pequenas emissoras locais colocando à prova a hegemonia das duas principais empresas radiofónicas existentes - a RDP pertencente ao estado e a Renascença, propriedade da Igreja Católica.

Tratou-se de um fenómeno que seguiu os movimentos semelhantes existentes um pouco por toda a Europa, mas com destaque para a Itália, Espanha, França e GrãBretanha, onde surgiram inúmeras estações locais com o objetivo de apoiarem determinadas causas sociais ou políticas, dar voz às populações locais ou simplesmente proporcionar diferentes momentos de rádio.

No caso português é evidente a influência que a mudança de um regime ditatorial para a democracia teve no surgimento de pequenos grupos de cidadãos dispostos a fazer ouvir a sua voz nas ondas hertzianas, criando pequenas emissoras que, por emitirem sem licença, ficaram conhecidas como rádios piratas.

As rádios locais representaram o renascimento de um novo espaço de liberdade (GUATTARI, 1981) e de expressão baseada na palavra direta e de livre acesso (ECO, 1981). Para Patrice Flichy (1981) o movimento das rádios locais que surgiu na Europa enaltece as potencialidades de interpretação alternativa do real. Ou seja, como as rádios de cobertura nacional não concedem a mesma atenção noticiosa a temas de uma certa especificidade local, cabe às emissoras de menor dimensão fazê-lo (NOSTY, 1997; CHANDLER \& HARRIS, 1997).

No presente texto, pretende-se analisar o período histórico (1977-1988) em que as rádios locais portuguesas emitiram sem licença e por isso foram apelidadas de "rádios-piratas". Foi um período de luta pela legalização que só chegaria com a lei de 1988. O artigo traça as diversas dimensões das rádios locais portuguesas (informação, propriedade, afirmação) antes da sua legalização e foi construído a partir de uma pesquisa documental da legislação, imprensa da época e bibliografia existente sobre esta temática. 


\section{Um contexto favorável}

As primeiras rádios locais em Portugal surgem no final dos anos 70 num cenário com algumas especificidades. Desde logo porque o país tinha acabado de sair de um período de quase cinco décadas de ditadura, durante o qual o setor da comunicação social não conheceu grande evolução.

Após a queda do regime em 1974, tem início um processo de nacionalização da radiodifusão portuguesa, do qual ficaram de fora a Rádio Renascença ao abrigo do acordo entre a Igreja católica e o estado português, e duas pequenas emissoras: a Rádio Altitude e a Rádio Clube do Centro, devido à sua "quase nula representatividade no espectro radiofónico nacional” (SEREJO, 2001:81).

Quando começam a surgir as primeiras rádios piratas em Portugal, em 1977 (MAIA, 1995; AZEVEDO, 2001), o cenário da rádio portuguesa pode ser caracterizado por um duopólio constituído pela RDP, emissora do Estado, e pela Rádio Renascença, pertencente à Igreja Católica.

As rádios locais em Portugal nascem, por isso, num contexto pósrevolucionário impulsionadas pela liberdade de expressão entretanto conquistada no país e que tinham como objetivo a criação de um palco para o discurso alternativo e de caráter local.

O sentimento das populações locais era o de que os seus assuntos raramente constituíam prioridade para as emissoras nacionais. Por isso, o fenómeno das rádios locais está intimamente ligado ao desejo das comunidades em aceder ao espaço público mediatizado que, de alguma forma, lhes era negado naquela época.

Há também que levar em linha de conta os ecos que chegavam a Portugal, vindos da Europa, onde o fenómeno das rádios livres adquirira uma força com algum significado, sendo de destacar os casos francês e italiano (CAZENAVE, 1980; ECO, 1981).

O fenómeno das rádios locais em Portugal recolheu forte apoio junto dos autarcas portugueses que participaram com frequência em ações com o objetivo de pressionar o poder central para legislar no sentido de legalizar as emissoras locais.

Outro fator que caracteriza o fenómeno das rádios piratas em Portugal é a juventude dos seus impulsionadores. Muitos não possuíam experiência profissional e, muito menos, no campo da comunicação social. O amadorismo foi, aliás, a imagem de marca de um número considerável de projetos. O jornal Expresso noticiava os 
resultados de um inquérito realizado aos criadores das rádios piratas portuguesas e no qual fica bem patente a diversidade de profissionais que faziam rádio naquela época:

Seja qual for a profissão em que se pense, é quase certo que iremos encontrar referida, pelo menos uma vez, numa ou noutra das respostas: do padeiro ao barman, do polícia ao magistrado, do militar ao funcionário municipal, do teólogo ao filósofo, passando pelo químico, pelo fotógrafo, pelo cabeleireiro. $\mathrm{E}$ por aqui nos ficamos... (Expresso, 9 de maio de 1987).

No final da década de 80 , a idade dos trabalhadores das rádios locais portuguesas situava-se entre os 17 e os 20 anos de idade. A simples curiosidade ou o desejo de tornar pública uma voz alternativa ao discurso produzido pelos média nacionais, a par de alguns conhecimentos ao nível técnico (necessários para a montagem do emissor) eram fatores, por si só, suficientes para criar uma estação de rádio local.

Montar uma estação de «rádio livre» é relativamente barato. O mais caro é o investimento inicial, na aquisição do emissor, da antena e demais aparelhagens: gravadores, gira-discos, amplificador, misturador e outros aparelhos, que qualquer um de nós encontra numa casa de electrodomésticos. (...) Com a actual tecnologia, miniaturizada e pouco dispendiosa, pode fazer-se rádio com quaisquer 10 contos. (Jornal de Notícias, 29 de Dezembro de 1983)

Não quer dizer que no período que aqui analisamos não tenham aparecido projetos com alguma solidez, quer ao nível de recursos humanos, quer ao nível financeiro. A TSF, o Correio da Manhã Rádio e a Radiogeste apresentaram investimentos avultados para a época e que representaram "um total de 120 postos de trabalho" (Jornal Tal\&Qual, 7 de outubro de 1988).

Mas a grande maioria das estações locais, particularmente as que surgiram até 1984, caracterizavam-se sobretudo pela escassez de meios técnicos, humanos e financeiros, sobrevivendo, nalguns casos, de pequenas dádivas dos seus fundadores ou, numa fase mais avançada, de parcas receitas publicitárias.

\section{As primeiras emissoras}

As primeiras emissões das rádios piratas em Portugal visavam sobretudo dois objetivos. Em primeiro lugar marcar uma posição junto da opinião pública e do poder político e por outro dar voz às populações locais que normalmente não apareciam nos noticiários das rádios nacionais. 
Assumiam deliberadamente uma posição de rutura com a rádio que se fazia na época. As próprias designações das rádios são disso um indicador: Rádio Delírio, Rádio Caos, Rádio Livre ou Rádio Porta Aberta.

A primeira rádio pirata de que há registo em Portugal é a Rádio Juventude, que surgiu em 1977 (MAIA, 1995; AZEVEDO, 2001) e que emitiu para a área da Grande Lisboa até ao dia 22 de janeiro de 1981, altura em que o seu emissor foi apreendido pelos Serviços Radioelétricos dos CTT, a entidade a quem competia fiscalizar a atividade de radiodifusão em Portugal.

Em 1979 apareceu a Rádio Imprevisto, cuja emissão era captada nos concelhos da Amadora, Queluz, Barreiro, Almada, Trafaria, Loures e Amadora, nos arredores de Lisboa. A programação da Imprevisto era composta por música dos chamados lados B dos discos, numa clara vocação para a emissão de temas musicais que as rádios nacionais ignoravam ou pelo menos não constituía a sua principal aposta ao nível da programação. Esta estação também não teve uma vida muito longa, já que no dia 25 de janeiro de 1981, o seu emissor foi apreendido.

Perante o encerramento da Juventude e da Imprevisto, os seus criadores resolveram juntar esforços e criar as Emissoras Associadas, uma rádio pirata que iniciou as emissões no dia 7 de fevereiro de 1982. O início dos anos 80 ficou marcado pelo aparecimento de várias rádios piratas um pouco por todo o país.

A facilidade com que se colocava no ar uma emissão de rádio ajudou à proliferação de pequenas estações locais, normalmente com pequena potência e que funcionavam, em muitos casos, na residência dos seus criadores.

Havia estações que emitiam a partir de vãos de escada e outras que funcionavam no quarto da residência do locutor, no qual a cama servia de sofá para os convidados. Nesta fase, o amadorismo marca a maior parte dos projetos radiofónicos de âmbito local, como ilustra o exemplo que o jornal Expresso noticiou:

O letreiro desenhado à mão - está colado na porta de ferro que dá entrada para a torre da igreja. $O$ insólito da situação acompanha o visitante que suba a escadaria de pedra: o som do órgão, que alguém toca dentro da igreja, ouve-se em simultâneo com o de uma qualquer música «rock» vinda lá de cima, da cabina, onde um jovem (aluno da escola secundária local) põe no ar a emissão (Expresso, 9 de maio de 1987).

Independentemente da notória falta de condições, a verdadeira intenção dos promotores de rádios piratas era a de colocar no ar uma emissão radiofónica vincando assim uma posição e ganhando espaço para a desejada liberalização do setor. 


\section{Dois períodos}

Consideramos dois períodos na história das rádios piratas portuguesas. $\mathrm{O}$ primeiro entre 1977 e 1984, altura em que o fenómeno se caracterizou pelo aparecimento de pequenas emissoras em vãos de escada, impulsionadas pela carolice e amadorismo dos seus criadores.

Mais do que criar bases sólidas para uma rádio, pretendiam despertar a opinião pública para um movimento que, salvo raras exceções, nunca se revestiu de organização e estrutura adequadas. Deve-se, contudo, assinalar o aparecimento, neste mesmo período, de projetos mais sólidos, como foi o caso da TSF.

Situamos o segundo momento entre 1985 e 1988, numa fase em que surgiram vários projetos com alguma dimensão e que visavam, já não apenas a afirmação de uma ideia, mas a legalização da radiodifusão local em Portugal.

Em relação ao primeiro período aqui considerado (1977-1984) torna-se difícil estabelecer com precisão o número de rádios que então terão aparecido, uma vez que se tratavam de emissoras pequenas, que emitiam ilegalmente algumas horas por dia e, em muitos casos, um ou dois dias por semana e tinham vida demasiado curta. Não havia, como é natural, um organismo onde fossem registadas, uma vez que emitiam sem licença.

Ao jornal Diário de Lisboa (25 de outubro de 1984), o então secretário-geral das Comunicações, Raúl Junqueiro, admitia pela primeira vez haver a funcionar em Portugal "com mais ou menos regularidade 19 estações de rádio das quais 14 foram observadas pela primeira vez em 1984".

Depois de 1985, e até à legalização, apareceram os projetos mais sólidos. Para isso, muito contribuiu o facto de muitas emissoras terem sido criadas por iniciativa de profissionais dissidentes das rádios nacionais.

Mas o grande boom das rádios locais em Portugal surge em 1986 quando, segundo a imprensa da altura, apareceram 71 novas emissoras em todo o país. Em 1987 - um ano antes da legalização - segundo o jornal Expresso (9 de maio de 1987), emitiam em Portugal, com maior ou menor regularidade, 419 rádios piratas.

As expetativas relativas à legalização das rádios locais em Portugal começavam a crescer e por isso nesta fase ganham forma alguns dos projetos mais 
consistentes de todo o período. É o caso da Rádio Cidade, uma emissora local da Amadora, perto de Lisboa, que tinha a particularidade dos seus locutores falarem português com sotaque brasileiro e de se dirigir ao público mais jovem, apresentando na sua programação os hits musicais do momento.

Outro exemplo é o Correio da Manhã Rádio. Tratou-se de um projeto iniciado no seio de uma empresa com tradições na comunicação social, pois já possuía o jornal com o mesmo nome. Talvez por essa razão os seus responsáveis tenham começado a emitir 24 horas por dia, uma realidade que poucas rádios na altura conseguiam acompanhar.

A TSF, rádio criada por um conjunto de profissionais dissidentes da rádio pública portuguesa, é sem dúvida um dos projetos mais sólidos surgidos durante o período das rádios piratas portuguesas. Os primeiros passos foram dados em $1981 \mathrm{com}$ a criação da TSF - Cooperativa de Profisssionais de Rádio constituída por jornalistas como Adelino Gomes, António Jorge Branco ou David Borges. Em 1984, a TSF fez a sua primeira emissão pirata durante quatro horas (MENESES, 2003:22). As emissões regulares da TSF só tiveram início no dia 29 de fevereiro de 1988.

\section{Propriedade e financiamento}

A maior parte das rádios locais foi criada por iniciativa individual ou por pequenos grupos de pessoas, normalmente ligadas à eletrotecnia que, por possuírem conhecimentos ao nível técnico lhes permitia montar (e retirar) com facilidade as antenas e assim escapar à físcalização dos serviços dos CTT.

Esta caracterização corresponde sobretudo aos primeiros anos do fenómeno em Portugal. Com o avançar dos anos, e com a consciencialização de que a atribuição de frequências poderia ser uma realidade, começaram a aparecer projetos que, sem ser arrojados quer ao nível de estruturas quer de investimentos financeiros, já se distanciavam das incipientes experiências iniciais.

Foi nessa altura que grupos de pessoas motivadas pela carolice acabaram por se formar em cooperativas de radiodifusão, uma condição preferencial, segundo a lei que viria a ser aprovada, para a obtenção de alvará.

A propriedade das emissoras piratas era muito diversa. Para além das que surgiram no seio de pequenas empresas há a considerar as que pertenciam à igreja 
Católica, à igreja Evangélica, a jornais locais, a clubes de futebol, a associações culturais e desportivas e até a organismos criados no seio das autarquias.

Antes de as rádios fazerem depender a sua sobrevivência da publicidade, eram financiadas das mais diversas formas. Para além dos investimentos, sempre muito modestos, que recebiam dos respetivos proprietários, as emissoras obtiveram apoios de inúmeras instituições. Os mais comuns provinham das próprias autarquias locais, através de programas camarários.

Mas houve também apoios que chegavam de Ligas dos Amigos, constituídas pelos ouvintes, e de pequenas empresas locais ou de maior dimensão.

Apesar de emitirem sem licença, os proprietários das rádios piratas encetaram uma luta para que pudessem receber receitas da publicidade alegando igualdade de oportunidades em relação às emissoras de cobertura nacional.

\section{Jornalismo de proximidade}

Os responsáveis pelas rádios locais perceberam que o campo da informação local poderia representar um importante território de afirmação do movimento ao disponibilizar para os ouvintes as notícias sobre os locais de cobertura que as emissoras nacionais dificilmente veiculariam.

Este era, afinal, um dos principais argumentos apresentados pelos impulsionadores das rádios locais portuguesas: que seria preciso levar para o espaço público protagonistas que em regra não cabiam nos noticiários das emissoras de Lisboa. Os repórteres das rádios locais esforçaram-se por levar para antena os problemas vividos pelos cidadãos, questionando os poderes políticos locais, enfim, afirmando-se como espaços de confronto e crítica social e contribuído para a memória coletiva da comunidade.

Um dos setores da informação que mais sobressaiu com o aparecimento das rádios piratas foi o desporto local. Foi notório o empenhamento nesta área, pois os responsáveis pelas emissoras percebiam que seria uma temática onde dificilmente as emissoras nacionais entrariam. Os relatos de futebol tornaram-se célebres e preencheram claramente uma lacuna sentida pelos ouvintes, que era o acompanhamento permanente e em direto do clube local. 
As rádios locais proporcionaram, por outro lado, a oportunidade a muitos jovens para entrarem na profissão de jornalista. Ao contrário do que sucedia, já não era necessário migrar para Lisboa ou Porto para ingressar no jornalismo. O jornal Expresso (9 de maio de 1987) noticiava que, das 126 rádios locais identificadas por aquele semanário, 20 não possuíam redação, 59 possuíam mas não existiam jornalistas profissionais e só 47 redações de emissoras locais eram coordenadas por jornalistas.

As rádios piratas debatiam-se, contudo, com fortes constrangimentos de ordem organizacional para colocar no ar os noticiários. A falta de recursos humanos e de meios técnicos foi uma realidade sentida por muitas emissoras locais. Poucas rádios recorriam a algo mais que ao press-release das câmaras municipais ou das empresas da região. As fontes de informação mais comuns eram, por isso, as institucionais, especialmente as que provinham das forças políticas locais, que viram nestas pequenas emissoras uma forma eficaz de fazer passar a sua mensagem, uma vez que isso seria pouco provável em meios de comunicação de maior dimensão.

A atualização das notícias nem sempre era possível, já que muitas informações chegavam às redações via correio. Algumas emissoras piratas de maior dimensão tinham na redação terminais de agências de notícias. O recurso a correspondentes locais ou a colaboradores ocasionais era frequente na maior parte das emissoras locais no período que antecede a sua legalização. Aproveitando o facto de muitas rádios locais pertencerem, ou terem apoios de jornais regionais ou locais, o recurso a estes como fonte de informação era também muito comum.

\section{As iniciativas legislativas}

O processo de legalização das rádios piratas portuguesas foi complexo. Entre 1983 e 1988 registaram-se várias iniciativas legislativas no sentido de legalizar a radiodifusão local portuguesa. Da parte das rádios faltou uma estrutura representativa que liderasse as negociações com os governos da altura.

Ocorreram, contudo, embora de forma pontual, alguns eventos que pretendiam debater e discutir as rádios locais em Portugal. Um deles foi a realização do I Encontro Nacional de Rádios Livres, a 18 de junho de 1983, em Vila Nova de Gaia. Aí, foi criada uma Comissão Coordenadora Nacional das Rádios Livres, destinada a encabeçar a luta pela legalização. 
Com um carácter mais regular, realizaram-se os Encontros de Abrantes. Representaram um dos poucos locais de debate organizado e discussão no período anterior à legalização das rádios locais em Portugal. Eram promovidos por alguns criadores de rádios piratas em Portugal, nomeadamente a Rádio Antena Livre, de Abrantes.

Os Encontros de Abrantes representaram um dos palcos de maior relevância para a discussão da radiodifusão local portuguesa, conforme recordou mais tarde ao jornal Público, António Colaço, um dos organizadores dos encontros:

Fizeram-se aqui, pelo menos, três encontros à escala nacional de todas as rádios do país. Os encontros de Abrantes ganharam muito protagonismo, não havia rádio que não passasse por aqui, chegámos a trazer cá deputados. (Jornal Público, 24 de dezembro de 1998)

Perante o cenário, cada vez mais evidente, da importância que as rádios locais começavam a adquirir, os radialistas percebiam a inevitabilidade de uma mudança na lei que contemplasse estas emissoras que, entretanto, já tinham adquirido apoio junto das populações e do poder autárquico.

A primeira iniciativa no sentido de legislar para legalizar as rádios piratas aconteceu em 1983 com o projeto dos deputados Dinis Alves e Jaime Ramos e sublinhava, de um modo geral, a importância da rádio para as comunidades locais.

Os autores do projeto-lei basearam-se em dois pressupostos. Por um lado, o alargamento da faixa de $87,5 \mathrm{MHz}-100 \mathrm{MHz}$ até aos $108 \mathrm{MHZ}$, o que permitiria considerar novos canais de radiodifusão em Portugal e por outro, a constatação da existência de uma camada de público ouvinte que se sentia insatisfeita com a programação das rádios de cobertura nacional.

As emissoras locais representariam uma forma alternativa para os consumidores de rádio. Os ouvintes passariam a dispor de "um poder mais alargado de escolha de programas mais variados e mais ajustados à especificidade das diversas regiões do país" (Preâmbulo do Projeto de Lei in MARCOS, 1989). O projeto de Dinis Alves e Jaime Ramos acabaria por não ser votado em sede parlamentar.

Em março de 1987, surge uma outra iniciativa no sentido de legalizar a radiodifusão local, mas esta lei nunca chegou a ser aplicada, pois foi revogada por aquela que viria a permitir o licenciamento das emissoras locais em Portugal: a lei 87/88 de 30 de julho.

Este diploma estipula que o exercício de radiodifusão é atribuído a empresas públicas, privadas e cooperativas. De acordo com o artigo sexto da lei, os fins da 
atividade privada e cooperativa seriam, entre outros, os de alargar a programação radiofónica a interesses, problemas e modos de expressão de índole regional e local, preservar os valores das respectivas culturas, difundir informações de interesse para a área geográfica de cobertura e incentivar as relações de solidariedade entre as populações locais.

Com a entrada em vigor da nova Lei da Radiodifusão, nos termos do seu segundo artigo, foi criado o decreto-lei 338/88 destinado a regulamentar o regime de licenciamento da atividade de radiodifusão. O decreto-lei respondia a preocupações já anteriormente manifestadas, nomeadamente a necessidade de incluir medidas que evitassem a excessiva concentração.

Aprovada a lei, o concurso público para a atribuição das frequências foi finalmente lançado em janeiro de 1989. A potência das frequências a atribuir (consideradas muito fracas) as acusações de governamentalização da Comissão Consultiva - que iria avaliar as candidaturas - causou nova agitação no setor.

Porém os maiores problemas surgiram a partir de uma outra medida. Enquanto durasse o período de avaliação das candidaturas, a legislação previa que as rádios que funcionavam na ilegalidade encerrassem as emissões acreditando que desta forma as emissoras não pressionariam o processo de decisão.

A medida acabou por ser cumprida no dia 24 de dezembro de 1988, não sem que antes as rádios protestassem contra ela, naquele que ficou conhecido como o Dia da Rádio. Tratou-se de uma emissão em cadeia, na qual participaram duas centenas de rádios em protesto contra o período do silenciamento e que teve lugar no dia $17 \mathrm{de}$ novembro de 1988 a partir dos estúdios da TSF, em Lisboa. Entre as 7 e as 20 horas recriou-se o ambiente de um debate parlamentar convidando para a antena deputados da Assembleia da República.

Este episódio não foi suficiente para que algo mudasse no plano legislativo e o concurso público para atribuição de alvarás foi lançado com pouco mais de 400 frequências disponíveis em todo o país. Um número, mesmo assim, inferior ao que se estimava ser a quantidade de emissoras piratas a emitir em Portugal. Os primeiros alvarás acabariam por ser atribuídos no primeiro trimestre de 1989 a seis rádios em Lisboa e cinco no Porto.

A atribuição de frequências criou, contudo, uma nova realidade no cenário radiofónico que viria a caracterizar os primeiros anos da radiodifusão local póslegalização. Se nos concelhos do litoral faltaram frequências para as candidaturas 
apresentadas, no interior restaram outras por atribuir tendo em conta a escassez de emissoras piratas que se apresentaram a concurso. O cenário resultante foi, por isso, de uma profunda assimetria entre estas duas zonas do país.

\section{Conclusões}

O período que procurámos caracterizar ao longo deste texto representa um dos maiores movimentos no setor dos média em Portugal e deve ser enquadrado num processo de amadurecimento da então jovem democracia portuguesa.

Uma primeira nota que se deve considerar é que a proliferação de pequenas emissoras locais pelo país teve, na maior parte dos casos, origem na iniciativa dos cidadãos, que assim procuraram a criação de um espaço de afirmação das especificidades locais e de construção de uma memória coletiva. À semelhança daquilo que se verificou noutros países europeus, também em Portugal foi mais fácil criar uma estrutura, ganhar audiência do que obter a tão desejada licença para emitir. O processo legislativo com vista à liberalização do setor demorou vários anos, reflexo das intermitências das forças políticas que geriram o país naquela época.

As rádios locais representam, pois, um fenómeno singular no panorama mediático português dada a sua "origem popular e de bricolage", como referiu Flichy (1981). Permitiram, tal como tentámos demonstrar, o alargamento do espaço mediático, criando momentos de proximidade com as populações e democratizando o acesso às profissões ligadas à comunicação. Por outro lado, foi a legalização das rádios locais portuguesas que permitiu o aparecimento de emissoras com um discurso diferente quer ao nível da sua programação quer da informação e que ainda hoje perduram. A TSF é o caso mais evidente.

As rádios locais portuguesas devem, por isso, ser enquadradas num processo de transição do país, saído de quase cinco décadas de ditadura para um regime democrático e que evidenciou através dos inúmeros projetos radiofónicos surgidos a expressão da sua cidadania. 


\section{Bibliografia}

AZEVEDO, Ana Paula, As rádios locais no pós-25 de Abril, Observatório, nº, 2001, pp.113-122.

BONIXE, J. Luís, As rádios locais em Portugal: Informação e função social -Uma análise dos noticiários das rádios do distrito de Setúbal, Dissertação de Mestrado defendida na Universidade Nova de Lisboa, 2003.

CAZENAVE, François, Les Radios Libres, Paris: PUF, 1980.

CHANTLER, P. \& HARRIS, S., Local Radio Journalism, Oxford: Focal Press, 1997.

ECO, Umberto, Una nueva era en la liberdad de expresión. In De las Ondas Rojas a las Radios Libres, BASSETS, Lluís (ed.).Barcelona: Gustavo Gili. 1981, pp. 213-230.

FLICHY, Patrice, La explosión del monólogo. Las radios paralelas en la Europa Occidental.In De las Ondas Rojas a las Radios Libres, BASSETS, Lluís (ed.).Barcelona: Gustavo Gili, 1981. pp, 180-188.

GUATTARI, Félix, Las rádios libres populares. In De las Ondas Rojas a las Radios Libres, BASSETS, Lluís (ed.).Barcelona: Gustavo Gili, 1981, 231-236.

HENDY, David, Radio in the Global Age, Cambrige: Polity Press, 2000.

MAIA, Matos, A Telefonia, Lisboa: Círculo dos Leitores, 1995.

MARCOS, Luís Humberto, Rádios Locais - A lei e a realidade, Porto: Centro de Formação de Jornalistas do Porto, 1989.

MARINHO, Sandra, Um percurso da rádio em Portugal. In A Comunicação e os Media em Portugal, Pinto, Manuel (Coord.), Braga: Universidade do Minho. 2000, pp. 99-109.

MENESES, João Paulo, Tudo o que se passa na TSF, Lisboa: Jornal de Notícias, 2003.

MESQUITA, Mário (1994). Os Meios de Comunicação Social, In 20 anos de democracia em Portugal, REIS, António (coord.). Lisboa: Circulo dos Leitores, 1994, pp. 360-405.

NOSTY, B. D., Los medios públicos regionales y locales - El futuro de los canales autonómicos y los medios locales públicos. In ESCUDERO, Manuel Chaparro (ed.), Radiotelevisión Pública Local y Alternativa - Perspectivas, Sevilla: Asociación de Emisores Municipales de Andalucía de Radio y Televisión, 1997, 157-172.

SEREJO, Fernando, Rádio - do Marcelismo aos nossos dias (1968-1990), Observatório, no 4, 2001, pp. 65-95.

SANTOS, Rogério, A Rádio em Portugal: tendências e grupos de comunicação na actualidade, Comunicação e Sociedade, $\mathrm{n}^{\circ}$ 7, 2005, pp. 137-152.

Este artigo e todo o conteúdo da Estudos em Jornalismo e Mídia estão disponíveis em http://www.periodicos.ufsc.br/index.php/jornalismo/index

Estudos em Jornalismo e Mídia está sob a Licença Creative Commons. 